\title{
Exploring the meaning and origin of stereotypes amongst South African employees
}

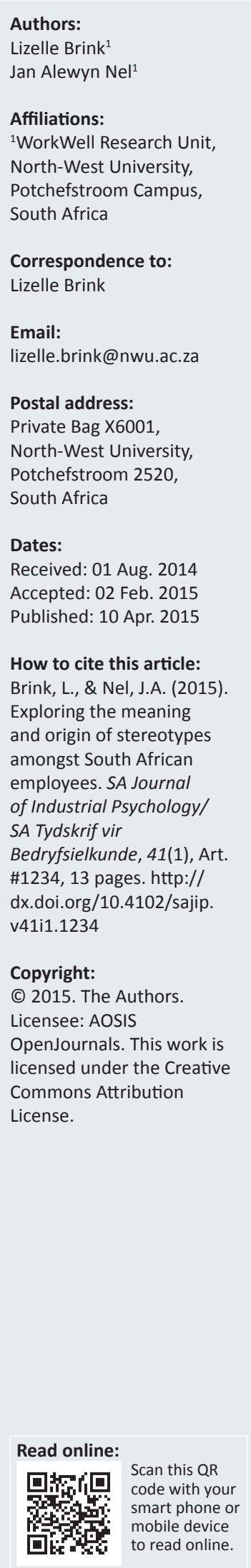

Orientation: Stereotypes are defined in different ways and also originate from various sources.

Research purpose: To investigate how the employees from selected South African organisations understand and define the concept 'stereotype' and what the origins of stereotypes are.

Motivation for the study: Individuals hold different perceptions of the same concept. Therefore, different individuals within selected South African organisations may interpret the meaning and origin of stereotypes very differently. This study therefore aimed to discover whether individuals have a shared understanding of the concept of stereotypes and whether they are aware of where stereotypes originate from.

Research approach, design and method: A combination of both purposive and convenience sampling was used for the purpose of this study. The sample consisted of individuals working in selected South African organisations $(N=336)$. Various employment sectors formed part of this study. Semi-structured interviews were utilised to collect data and data analysis was done by making use of thematic analysis.

Main findings: The results of this study indicated that people employed in selected South African organisations are familiar with stereotypes and have a clear understanding thereof. Participants in this study have a conscious awareness of the origin of stereotypes. Although not all of the participants had direct experiences with stereotyped groups, they were well aware that stereotypes are also caused by indirect sources.

Practical implications/managerial implications: When individuals are aware of where their stereotypes originate, they should actively attempt not to rely on their stereotypes when coming into contact with stereotyped groups. Organisations should educate their employees on the process of stereotypes and exactly what this means and where they originate from.

Contribution/value-add: With this study the emic perspective pertaining to the meaning and origin of stereotypes is explored within the South African context. By participating in this study, individuals may become aware of the fact that their perceptions and opinions of others may be based on inaccurate information. This study may encourage individuals to truly get to know someone first rather than relying on their possibly inaccurate stereotypes.

\section{Introduction}

The phenomenon of stereotypes has been studied since the early 1900s (Allport, 1954) and, even today, this phenomenon exists in the broader society as well as within many organisations across the globe (Jussim, 2012; Mullins, 2010). A wide variety of individuals are commonly stereotyped, such as, amongst others, managers, supervisors and individuals from varying demographic groups, such as race, gender and age (Luthans, 2010). Such stereotyping can lead to negative consequences within domains such as the workplace. It can lead to problems such as unintelligent decisions, problems with communication and in general contribute to the forming of different opinions and beliefs about individuals or employees different from ourselves (Jenifer \& Raman, 2015). Consequently, organisations have become more focused on managing these stereotypes and their negative consequences.

However, much confusion exists regarding the phenomenon of stereotypes. During the past three decades, stereotypes have been misunderstood in their scientific area (Jussim, 2012). There exists no specific definition of stereotypes that is commonly accepted; researchers in the realm of stereotypes have, however, agreed that stereotypes do consist of conventional aspects such as attributing characteristics to different social groups (Lee, Jussim \& McCauley, 2013). Furthermore, there is not only one, but many sources that can contribute to the formation of stereotypes. For example, the social environment in which one interacts can contribute to the formation of stereotypes, including 
sources such as parents, family members, media, peer groups and schools (Bar-Tal, 1996). It seems that there are various ontological and epistemological stances behind stereotyping, which highlights the importance of this study and is the reason for using the social constructivism paradigm as the framework for this study. Furthermore, because stereotype research within South Africa is limited and mostly focused on content-specific research (see for example Adhikari, 2006; Holtzhausen, Jordaan \& North, 2011; Wessels \& Steenkamp, 2009), it is unclear to the authors whether South Africans are truly familiar with the meaning and origin of stereotypes. Therefore, the purpose of this study was to explore from an emic perspective how stereotypes are understood by individuals within their work context, and how stereotypes develop.

\section{Research purpose and objectives}

Internationally, the meaning and origin of stereotypes has been researched; however, with this study the emic perspective pertaining to the meaning and origin of stereotypes is explored within the South African context. The objective of this study is therefore to understand how South African employees define the concept stereotypes and how, according to them, the process of stereotyping starts. Following are a literature study, empirical study, discussion and limitations and recommendations.

\section{Literature review Conceptualisation of stereotypes}

The term stereotype was first coined by Lippmann in 1922 (as cited in Dovidio, Hewstone, Glick \& Esses, 2010) in order to describe a social group's perceived characteristics. Furthermore, according to Allport (1954, p. 191), a stereotype is an 'an exaggerated belief associated with a category. Its function is to justify (rationalise) our conduct in relation to that category'. This definition is often quoted in a great deal of stereotype research, especially since Gordon Allport (1954) was a well-known psychologist in his time and author of The nature of prejudice (Dovidio et al., 2010). Furthermore, it was found that various social psychologists (see Dividio et al., 2010) in the last five decades utilised Allport's writings as a foundation for their own work. This definition provides an indication of many of the conventional aspects of stereotypes (Pickering, 2001). When explaining the definition of stereotypes as mentioned by Allport, it can be seen that stereotypes inflate and homogenise traits that are seen to be characteristics of specific categories; in other words, these traits are generalised or classified to all individuals forming part of this specific category (Pickering, 2001).

Categories (or social groups) can be defined by any number of criteria, such as race, gender, occupation and age (Arnold et al., 2010; Bergh \& Theron, 2009). Once these social groups are formed, beliefs or perceptions usually exist about the characteristics, attributes or behaviours of members belonging to that particular group or category (Hilton \& Von Hippel, 1996; Whitley \& Kite, 2006). Most often, a person is stereotyped because the perceiver (the one doing the stereotyping) is only familiar with the overall category or group to which the person belongs (Luthans, 2010). Other research, however, has proposed that many people who stereotype do not have broad stereotypes, for example all women, or all men, but that stereotypes are often made about people belonging to a specific group such as old men or old white women (Arnold et al., 2010; Stangor, Lynch, Duan \& Glass, 1992). This possibly means that individuals who have more information available to them may make use of more specific stereotypes than individuals who rely on broader stereotypes because of a lack of information.

When thinking about stereotypes, individuals are inclined to believe that all stereotypes are negative in nature; however, this is untrue. Stereotypic beliefs or perceptions can be positive (e.g. 'Asians are good students and employees'), negative ('senior citizens are too old to be good employees') or neutral ('Australians like cricket') (Mullins, 2010; Whitley \& Kite, 2006). Literature provides examples of the nature of stereotypes ascribed to groups. Because each individual is unique, it should not be assumed that the actual traits, characteristics or behaviours of the person being stereotyped will concur with those that are suggested by the stereotype (Luthans, 2010). These stereotypes assigned to groups are usually seen to be simplistic, inflexible and inaccurate, and these stereotypes can hurt the personal and social identities of individuals (Pickering, 2001). Stereotypes have a damaging effect, especially since stereotypes do not recognise the differences in social groups and often lead to inaccurate perceptions and inappropriate behaviour towards people (Bergh \& Theron, 2009). This does not mean, however, that all stereotypes are incorrect; many stereotypes have a kernel of truth (Whitley \& Kite, 2006). McShane and Von Glinow (2014) concur with this, being of the opinion that not all stereotypes are exaggerations or falsehoods, but that stereotypes often have some extent of truthfulness. Therefore, when stereotyping, individuals should not fall into the trap of believing that all stereotypes are a clear representation of all members belonging to a specific group.

\section{Origin of stereotypes}

In reviewing the literature, the authors noticed that there are numerous epistemological stances with regard to stereotypes. The authors will therefore make an effort to provide the reader of this article with a broad picture of the origin of stereotypes. With the globalisation of media coverage over the last few decades, it seems that mass media (which include movies, television and advertisements) are overflowing with stereotypes and are a main source of stereotypes learned by individuals (Plous, 2003; Whitley \& Kite, 2006). Although stereotyping has not been created by the media, modern media have a huge influence on generation and maintenance of stereotypes (Cooke-Jackson \& Hansen, 2008). Stereotypical images portrayed in the media are an everyday occurrence, and these stereotypical representations may cause prejudice towards out-groups, leading people to have negative and 
emotional feelings towards members of these groups (Ramasubramanian, 2005).

Apart from the media, where else does stereotyping originate from? Is it from childhood or influences from the work context? It is possible that stereotypes that employees hold within the workplace may have originated from various sources in their lives, which they may have transferred to the workplace. Individuals may form stereotypes and specifically assign attributes to certain groups that they may have indirectly learned from influential agents such as parents, teachers and peer groups (Timberlake \& Estes, 2007). Parents and other family members are primarily the sources that provide information and strengthen and teach stereotypic beliefs to children, and people may have retained these beliefs throughout their adult lives (Bar-Tal, 1996; Whitley \& Kite, 2006). Bar-Tal (1996) investigated the perceptions that Jewish children in Israel have of Arab people. Results of the study indicated that many of the children had negative stereotypic beliefs of Arabs and associated them with characteristics such as being violent and aggressive. Many of the children also mentioned that their parents (either their mother or father) described Arabs in a negative manner and also warned them to stay away from Arabs. These images that Jewish children developed in childhood may spill over to and be retained in adulthood (Whitley \& Kite, 2006).

According to the social learning theory (Barkley, 1982), people learn social behaviour through direct experience (for example by being rewarded or punished for behaving in a certain way) or through the observation of others (for example by observing the consequences of others' actions). People will therefore uphold those beliefs and behaviour for which they or others are rewarded and put an end to those beliefs and behaviours that will lead to them or others being punished (Whitley \& Kite, 2006). By taking this theory into consideration, it can be said that employees can learn to stereotype others because of their direct experiences with a specific group, or by learning stereotypes from influential others (Whitley \& Kite, 2006); however, by not being reprimanded for stereotyping others, individuals continue to engage in the process of stereotyping (Ramasubramanian, 2005).

\section{Research design}

The research design consists of the research approach, research strategy and research method.

\section{Research approach}

This study was qualitative in nature. In qualitative research, the researcher attempts to understand and explore the significance that individuals or groups of individuals attribute to a certain social or human problem, in this case stereotypes (Creswell, 2009). By doing qualitative research, the authors could study an occurrence or event and all that it entails such as its characteristics, qualities and properties (Botma, Greeff, Mulaudzi \& Wright, 2010).
Qualitative researchers working from the social constructivism paradigm believe that the social world is dynamic and complex (Botma et al., 2010). This may seem a true verification for the context of South Africa, since the world of work includes diverse employees who vary with regard to culture, language, race, gender, age, socio-economic status and education (Nel et al., 2012). Furthermore, within this paradigm, it seems that individuals construct their own reality of the social world; therefore, it may be that individuals construct their own reality and meaning when it comes to stereotypes (Botma et al., 2010; Hansen, 2004). The meanings that individuals attach to their realities may also be influenced by their interaction with other individuals, as well as influenced by the cultural and historical contexts within which they live (Creswell, 2009).

\section{Research strategy}

Keeping in mind the general objective of this study (to explore the meaning and origin of stereotypes amongst South African employees) the authors decided to implement a multiple case study strategy to collect relevant data. The authors therefore aimed to capture the views of multiple cases in order to get an overall picture of what participants believe about the meaning and origins of stereotypes. By making use of this strategy, the researcher investigated the perspective of multiple participants from multiple organisations in order to achieve a holistic understanding of the phenomenon of stereotypes (Niewenhuis, 2010). Therefore, the researcher was interested in the views of multiple case studies in order to answer 'how' and 'why' questions (Niewenhuis, 2010). Additionally, with a multiple case study strategy the authors focused on the replication logic of data, and not sampling logic (Yin, 1994). With replication logic the frequency a category or theme occurred in the study can be calculated in order to determine its importance.

\section{Research method}

The research method consists of the research setting, entrée and establishing researcher roles, sampling, research procedure, data collection methods, data recording, strategies employed to ensure data quality and integrity, ethical considerations, data analysis and reporting style.

\section{Research setting}

Numerous employment sectors were included to form part of this research study in order to gain a holistic understanding (as gathered from multiple cases) of the concept of stereotypes as experienced by employees within the South African work setting. Employment sectors that were included in this study were: banking, higher education institutions, mining, municipalities, nursing, police services, primary and secondary schools and the restaurant industry. Within these sectors, organisations were selected and approached for their employees to participate. After this process, full-time employees were asked to participate in this study within the selected organisations. Interviews were conducted by either 
the authors or trained fieldworkers and stretched over a period of three months.

\section{Entrée and establishing researcher roles}

The authors had to fulfil various roles throughout this research study. In order to execute this specific research study, it was important for the authors to first fulfil the role of planner. Here, the authors planned the study by paying attention to aspects such as sampling, data collection and analysis of the data. The next roles that both the authors and fieldworkers fulfilled were the roles of interviewers, active listeners and transcribers (Creswell, 2009). During this phase, the participants were asked questions specifically pertaining to what they understand regarding the meaning and origin of stereotypes. Thereafter, the authors, fieldworkers and several independent co-coders fulfilled the roles of data analysts. This process was done rigorously in order to truly capture the meaning and origin of stereotypes by participants. Throughout the entire research process, the authors and fieldworkers made every effort not to influence the participants or data by their own values and beliefs (Creswell, 2009).

\section{Sampling}

A combination of both purposive and convenience sampling was used for this research. When using purposive sampling, the sample is based on the judgement of the researcher; this means that participants are chosen to be included in research because they will be able to answer the 'how' and 'why' questions of the specific study (De Vos, Strydom, Fouché \& Delport, 2011). A convenience sample is chosen on the basis that participants are easily and conveniently available (Maree \& Pietersen, 2010). Using the combined approach, sectors were identified beforehand because they were conveniently accessible for the authors and fieldworkers (who assisted in data collection). With the purposive approach, organisations were selected if they functioned within the chosen employment sectors and if they employed more than 50 full-time employees. Also, employees were targeted who were as far as possible diverse in nature (i.e. in terms of race, gender, age, occupation, job level). Convenience sampling was used in order to target individuals from the selected organisations. By including diverse individuals working in selected organisations from various employment sectors, the researchers believed that they could gain a holistic understanding of the meaning and origin of stereotypes as experienced by participants within the South African work context.

The sample consisted of 336 employees from selected South African organisations. Characteristics of the participants are indicated in Table 1.

More than half of the participants were female (59\%), white (56\%), Afrikaans-speaking (57\%) and had obtained higher education or training (71\%). Almost half of the participants resided in North-West (45\%), whilst 23\% resided in Gauteng. Of all the participants, $25 \%$ were employed within primary
TABLE 1: Characteristics of participants $(N=336)$

\begin{tabular}{|c|c|c|c|}
\hline Item & Category & $f$ & $\%$ \\
\hline \multirow[t]{5}{*}{ Race } & Black & 104 & 31.00 \\
\hline & Mixed-race & 32 & 9.50 \\
\hline & Indian & 11 & 3.30 \\
\hline & White & 188 & 56.00 \\
\hline & Other & 1 & 0.30 \\
\hline \multirow[t]{2}{*}{ Gender } & Male & 137 & 40.80 \\
\hline & Female & 199 & 59.20 \\
\hline \multirow[t]{16}{*}{ Language } & Afrikaans & 195 & 58.00 \\
\hline & English & 47 & 14.00 \\
\hline & isiZulu & 7 & 2.10 \\
\hline & Sesotho & 14 & 4.20 \\
\hline & Setswana & 30 & 9.00 \\
\hline & Shona & 4 & 1.20 \\
\hline & Tshivenda & 4 & 1.20 \\
\hline & isiXhosa & 8 & 2.40 \\
\hline & Sepedi & 5 & 1.50 \\
\hline & Setswana & 1 & 0.30 \\
\hline & Xitsonga & 1 & 0.30 \\
\hline & *Afrikaans / English & 7 & 2.10 \\
\hline & *English / Setswana & 10 & 3.00 \\
\hline & *English / isiZulu / isiXhosa / Sesotho & 1 & 0.30 \\
\hline & *SiSwati / Sesotho & 1 & 0.30 \\
\hline & Missing values & 1 & 0.30 \\
\hline \multirow[t]{5}{*}{ Qualification } & Higher education and training (NQF level 5) & 238 & 70.80 \\
\hline & Further education and training (NQF level 4) & 84 & 25.00 \\
\hline & General education and training (NQF level 3) & 6 & 1.80 \\
\hline & From Grade 1-9 (NQF level 2) & 2 & 0.60 \\
\hline & Missing values & 6 & 1.80 \\
\hline \multirow[t]{9}{*}{ Province } & Free State & 47 & 14.00 \\
\hline & Gauteng & 80 & 23.80 \\
\hline & KwaZulu-Natal & 8 & 2.40 \\
\hline & Limpopo & 9 & 2.70 \\
\hline & Mpumalanga & 17 & 5.10 \\
\hline & North West & 152 & 45.20 \\
\hline & Northern Cape & 21 & 6.20 \\
\hline & Western Cape & 1 & 0.30 \\
\hline & Missing values & 1 & 0.30 \\
\hline \multirow[t]{8}{*}{ Employment sector } & Banking & 40 & 11.90 \\
\hline & Higher education institution & 72 & 21.40 \\
\hline & Mining & 63 & 18.80 \\
\hline & Municipality & 24 & 7.10 \\
\hline & Nursing & 4 & 1.20 \\
\hline & Police services & 20 & 6.00 \\
\hline & Primary and secondary school & 85 & 25.30 \\
\hline & Restaurant industry & 28 & 8.30 \\
\hline
\end{tabular}

*, These individuals are exposed to a multi-linguistic home setting.

and secondary schools, whilst $21 \%$ were employed within higher education institutions.

\section{Data collection methods}

Various fieldworkers assisted the authors with data collection by conducting semi-structured interviews with the participants. By making use of semi-structured interviews, researchers are able to obtain a detailed picture of the viewpoints and explanations that participants have about a specific topic (De Vos et al., 2011). Therefore, by conducting semi-structured interviews, the authors of this study were able to explore different realities that participants have regarding the meaning and origin of stereotypes. 
The following questions were asked in order to reach the objectives of this study:

1. In your own words, please explain what you understand about the word 'stereotype' ("What does the word 'stereotype' mean to you?")

2. What are the origins of stereotypes? ("Where do they come from?")

If the participants were not able to answer the first question, they were provided with a descriptive definition of the term 'stereotype', after which the interview proceeded and the question was asked again. In order to ensure that participants correctly understood the questions, a pilot study was conducted with nine participants working in the mining industry and higher education institutions. During the pilot study, questions were refined before starting with the data collection. After each interview, participants were asked to complete a brief biographical questionnaire.

\section{Data recording}

Interviews were tape-recorded with the permission of the participants in order to capture the exact spoken words of the participants when answering the two interview questions. After the interviews were conducted, the interviews were transcribed verbatim by either the authors or the fieldworkers. The fieldworkers were instructed to send their transcribed data to the authors, who conducted quality control concerning the content of the interviews. By doing this, the authors were able to get a feel for the data even before data analysis began. Furthermore, the authors made sure that all recorded data was safely and securely stored.

\section{Strategies employed to ensure data quality and integrity}

Various criteria were employed to ensure the trustworthiness of the findings, which is an important issue to consider during the research process. For the authors of this study, four aspects were deemed important.

Dependability: The authors ensured dependability by documenting all phases of the research process, especially concerning the write-up of the methodology of this research.

Credibility: It was important that the findings were reported according to what the data says (in terms of the meaning and origin of stereotypes), as collected from participants. The truth of the data should not be influenced by the preconceived convictions of the authors. By employing co-coding and rigorous discussions with independent researchers, the authors of this study ensured credibility by truthfully reporting the experiences of participants specifically with regard to the meaning and origin of stereotypes.

Transferability: Transferability also refers to generalisability. Generalisability can be described as the manner in which the conclusions of the research can be transferred to other contexts and settings (Durrheim \& Wassenaar, 2002). Since multiple case studies were utilised (different sectors and selected organisations), the meaning and origin of stereotypes could be better transferable to the overall work context of South Africa and to some extent be generalisable.

Confirmability: This also refers to objectivity (De Vos et al., 2011). The authors ensured that they remained impartial throughout the whole study by truly capturing the meaning and origin of stereotypes as reported by participants.

\section{Ethical considerations}

Ethical strategies were employed throughout the research. The authors and fieldworkers adhered to three important ethical considerations during the entirety of the research study (Welman, Kruger \& Mitchell, 2005).

Informed consent: Selected organisations were first approached to conduct the study amongst their full-time employees. The organisations were informed of the objective of this research, after which they granted permission. The employees were approached and the objective of the study communicated. They were also informed that they could withdraw from the study at any given time. The consent given by participants meant that they felt comfortable to proceed with this study.

Right of their privacy: Employees who participated were assured that their identity will remain confidential and that information will not be shared with their employers or any other individual whose name was not mentioned in the informed consent letter. Organisations were assured that their participation in this study will be kept confidential. Therefore, the authors and fieldworkers at all times during the research process did not mention the names of any individual or organisation.

Protection from harm: The authors and the fieldworkers assured the participants that they would not be emotionally or physically harmed during the course of this research; therefore, expectations from all involved parties were clarified from the onset of the research process in order to make the research process clear to the participants.

\section{Data analysis}

The authors made use of thematic analysis to interpret the data that were collected. According to Braun and Clarke (2006), thematic analysis is a tool used by researchers to help them identify, analyse and report patterns or themes that have been found within data that has been collected. The authors made use of Braun and Clarke's six steps in order to adequately analyse the data for this study.

\section{Step 1: Becoming familiar with the data}

Interviews were transcribed verbatim. Since 336 interviews were conducted, the assistance of the fieldworkers was used in 
this process. In order to ensure quality, the authors randomly checked transcribed interviews from each fieldworker. All transcribed interviews were then added together to form one large dataset. The authors read through the entire dataset and therefore became immersed in the data.

\section{Step 2: Generating initial codes}

Codes (categories in this case) were developed during this phase. The categories were labelled meaning of stereotypes and origin of stereotypes. The authors ensured the rigour of this step by paying equal attention to all raw data, and not disregarding data that seemed insignificant at the time.

\section{Step 3: Searching for themes}

From the two categories identified in the previous step, the authors were now able to develop preliminary themes. The authors created overarching themes for each category and documented the themes and accompanying responses for each category, after which sub-themes were also created.

\section{Step 4: Reviewing themes}

During this step, the themes identified in the previous step were refined. The authors ensured that the sub-themes and responses assigned to each theme were indeed an accurate reflection of the theme. The entire dataset was once again studied by the authors in order to ensure that all responses had been coded and that all themes and sub-themes were assigned correctly to each category.

\section{Step 5: Defining and naming themes}

Themes were further refined by the authors by providing an indication of the important aspects that underlie each theme. An analysis for each theme was written (see findings). The authors also determined the relatedness of each theme. Where necessary, sub-themes were also refined. After the refinement of themes and sub-themes, the authors were able to explain the content of each theme by only making use of a few sentences (see findings). The authors ensured that the names of themes and sub-themes are indeed a clear representation of the themes given.

\section{Step 6: Producing the report}

The authors ensured that the findings pertaining to the data were clearly and accurately explained to the reader. The authors, together with various independent co-coders, analysed the data. Co-coders were employed in either the industrial psychology or human resource management field.

\section{Reporting style}

After the data analysis, categories, themes and sub-themes were reported in table format and quotations were used to substantiate the results of the study. By including direct responses from participants, the reader can see that the authors reported the findings of this study in an ethical manner.

\section{Results}

The findings of the study were organised into categories, themes and sub-themes. Below, the categories, together with relevant themes and sub-themes will be provided in various tables. Quotations that support the findings are also included within the tables. The frequency of the themes mentioned is also indicated in brackets next to each theme. The frequency of responses does not indicate the number of participants who mentioned a specific theme; rather, it indicates the number of times the themes recurred.

\section{Category 1: Meaning of stereotypes}

In this category, participants were requested to provide a detailed description of the term 'stereotype'.

Table 2 provides a description of themes and sub-themes as extracted from the analysed data. Examples of original responses by participants were also provided in order to substantiate the findings of this category. It is evident that participants differed in terms of the meaning they attach to stereotypes. Below are the descriptions of the meaning of stereotypes as provided by the different participants.

Assumptions: Stereotypes are assumptions made about people. These assumptions are made based on the behaviour of the people observed, one's own ignorance, narrowmindedness or individual past experience with a particular person. When assumptions are made, individuals assign behaviours, characteristics and physical attributes to others. These assumptions may be accurate or inaccurate.

Beliefs: Participants perceive stereotypes to be beliefs about people. These beliefs may be based on a person's physical attributes or religion. The origin of these beliefs is because of one's own ignorance, narrow-mindedness or a past experience with a person. Because of these beliefs, a person is also thought to behave in a certain way. These beliefs may not always be accurate.

Categorisation: Stereotypes are viewed as dividing people into different categories based on various factors such as assumptions, behaviour, beliefs, characteristics, ignorance, occupation, past experience, physical attributes, social status and views of society. When categorising people, they are also believed to have certain characteristics or behave in a certain way. These categorisations may be accurate or inaccurate.

Differences: Stereotypes are perceived to be differences between individuals. These may be differences based on culture or physical attributes such as gender and race.

Discrimination: Stereotypes are when people discriminate against each other based on their physical attributes such as race and gender. 
TABLE 2: Meaning of stereotypes.

\begin{tabular}{|c|c|c|}
\hline Theme & Sub-theme & Response \\
\hline \multirow[t]{8}{*}{ Assumptions (24) } & Accurate or inaccurate & 'You make your own conclusion whether it's right or wrong.' \\
\hline & Assign behaviour & $\begin{array}{l}\text { 'Because I have an Asian surname, people assume that I will react to them or } \\
\text { behave in ways that they have experienced with other Asian people'. }\end{array}$ \\
\hline & Assign characteristics & $\begin{array}{l}\text { 'To me it means assumptions made of other people or groups and in most cases } \\
\text { they are wrong assumptions about their characteristics'. }\end{array}$ \\
\hline & Assign physical attributes & 'Making assumptions about how people are supposed to look'. \\
\hline & Based on behaviour & $\begin{array}{l}\text { 'It is making general assumptions about someone because of previous general } \\
\text { behaviours'. }\end{array}$ \\
\hline & Based on ignorance & 'It is assumptions that are made without consideration of the facts'. \\
\hline & Based on narrow-mindedness & $\begin{array}{l}\text { 'A fixed way of thinking, making assumptions about groups of people without } \\
\text { any sort of allowance, to allow for flexibility in your thinking and it can be very } \\
\text { dangerous at times'. }\end{array}$ \\
\hline & Based on past experience & $\begin{array}{l}\text { 'Automatically assuming that because of such an experience that you've had } \\
\text { with an incident. ... Then everything that happens is because of that, you are } \\
\text { stereotyping'. }\end{array}$ \\
\hline \multirow[t]{7}{*}{ Beliefs (15) } & Accurate or inaccurate & 'My understanding of a stereotype is that it is a subjective belief'. \\
\hline & Assign behaviour & 'A stereotype is a common belief or idea or behaviour that is expected'. \\
\hline & Based on ignorance & 'When you have beliefs about a group before you have the facts right'. \\
\hline & Based on narrow-mindedness & $\begin{array}{l}\text { 'Stereotype means that you have a belief about a person that remains the same } \\
\text { every day and doesn't ever change'. }\end{array}$ \\
\hline & Based on physical attributes & $\begin{array}{l}\text { 'Stereotypes are feelings or beliefs about a person based on his physical } \\
\text { characteristics'. }\end{array}$ \\
\hline & Based on past experience & $\begin{array}{l}\text { 'Belief held of these people is subjective as it may be based on experience or } \\
\text { certain encounters with a certain person'. }\end{array}$ \\
\hline & Based on religion & $\begin{array}{l}\text { 'To me, a stereotype means a common belief relating to a specific type of } \\
\text { person, be it ... religious'. }\end{array}$ \\
\hline \multirow[t]{12}{*}{ Categorisation (121) } & Accurate or inaccurate & 'Sometimes you put people fairly or unfairly in such a category'. \\
\hline & Assign behaviour & $\begin{array}{l}\text { 'To place people in a particular box and assume that everyone in that box is the } \\
\text { same or will act the same'. }\end{array}$ \\
\hline & Assign characteristics & $\begin{array}{l}\text { 'If someone does not know me personally it is easy to be put into a certain } \\
\text { category and assume the type of person I am'. }\end{array}$ \\
\hline & Based on assumptions & $\begin{array}{l}\text { 'Stereotypes are when people are sort of divided into categories based on } \\
\text { assumptions'. }\end{array}$ \\
\hline & $\begin{array}{l}\text { Based on beliefs; based on } \\
\text { behaviours }\end{array}$ & 'You put them in certain categories based on similar behaviours or beliefs'. \\
\hline & Based on characteristics & $\begin{array}{l}\text { 'If you classify certain groups or people according to characteristics that they } \\
\text { have'. }\end{array}$ \\
\hline & Based on ignorance & $\begin{array}{l}\text { 'And I think this is due to lack of understanding and people like to categorise } \\
\text { something they don't really understand'. }\end{array}$ \\
\hline & Based on occupation & 'To categorise someone according to ... type of work, etc.' \\
\hline & Based on past experience & $\begin{array}{l}\text { 'I think it must be from past behaviour. If people experienced something bad } \\
\text { or good in the past I think it comes from there. Past experiences whereby you } \\
\text { start stereotyping and putting people in categories'. }\end{array}$ \\
\hline & Based on physical attributes & 'When a person or group is classified because of race'. \\
\hline & Based on social status & $\begin{array}{l}\text { 'Stereotyping is classifying, grouping, couple according to social status, } \\
\text { highlighting it, expressing your stereotype mentality'. }\end{array}$ \\
\hline & Based on views of society & $\begin{array}{l}\text { 'It means to classify a group, a person or people in a certain category based on } \\
\text { how society views that type of person'. }\end{array}$ \\
\hline \multirow[t]{2}{*}{ Differences (8) } & Based on culture & 'Differences between different cultures'. \\
\hline & Based on physical attributes & 'Different types of gender beliefs, races'. \\
\hline Discrimination (14) & Based on physical attributes & 'Discrimination based on age, gender'. \\
\hline Do not know the meaning of stereotypes (11) & No meaning & 'I don't really know what stereotypes are'. \\
\hline \multirow[t]{11}{*}{ Generalisation (164) } & Accurate or inaccurate & 'People who make generalisations about a group that can be ungrounded'. \\
\hline & Assign behaviour & $\begin{array}{l}\text { 'My understanding of stereotype is that you generalise about a specific } \\
\text { behaviour and you apply it to a group of people in general'. }\end{array}$ \\
\hline & Assign characteristics & $\begin{array}{l}\text { 'It is one attribute that is given for group of people, for example, all blondes are } \\
\text { dumb'. }\end{array}$ \\
\hline & Assign thoughts & 'Stereotyping is when a group of people think alike'. \\
\hline & Based on behaviour & $\begin{array}{l}\text { 'If you see one or two people behaving this way you generalise that males are } \\
\text { like that and to me that is the stereotype'. }\end{array}$ \\
\hline & Based on characteristics & $\begin{array}{l}\text { 'When you think bad about one person then everyone is bad with the same } \\
\text { characteristics as that one person'. }\end{array}$ \\
\hline & Based on ignorance & 'Generalise without getting to know them or know about their circumstances'. \\
\hline & Based on occupation & 'When we generalise about a certain ... job'. \\
\hline & Based on past experience & $\begin{array}{l}\text { 'This is when someone generalises a group about past events and the } \\
\text { conclusions are likely to be inaccurate'. }\end{array}$ \\
\hline & Based on physical attributes & $\begin{array}{l}\text { 'A stereotype is a generalisation made about a certain group of individuals, } \\
\text { based on race, gender'. }\end{array}$ \\
\hline & Based on religion & $\begin{array}{l}\text { 'To give a broad definition, it is groups of people who are the same, based on } \\
\text {... religion'. }\end{array}$ \\
\hline
\end{tabular}

Table 2 continues on the next page $\rightarrow$ 
TABLE 2 (Continues...): Meaning of stereotypes.

\begin{tabular}{|c|c|c|}
\hline Theme & Sub-theme & Response \\
\hline \multirow[t]{9}{*}{ Judgement (45) } & Accurate or inaccurate & $\begin{array}{l}\text { 'Judgmental opinions on individuals from that particular group. Usually these } \\
\text { stereotypes tend to be unfair'. }\end{array}$ \\
\hline & Based on abilities & 'To judge someone based on his or her abilities'. \\
\hline & Based on background & 'They judge their ... background and any other such traits'. \\
\hline & Based on behaviour & 'It is when people judge each other based on ways or behaviours'. \\
\hline & Based on characteristics & $\begin{array}{l}\text { 'It is when people judge you because you have a certain aspect or character } \\
\text { trait'. }\end{array}$ \\
\hline & Based on ignorance & $\begin{array}{l}\text { 'Stereotype is when you judge people without knowing them and labelling } \\
\text { them on grounds of what you have heard'. }\end{array}$ \\
\hline & $\begin{array}{l}\text { Based on own beliefs; based on } \\
\text { expectations }\end{array}$ & $\begin{array}{l}\text { 'You judge people and their behaviour based on your own beliefs and } \\
\text { expectation'. }\end{array}$ \\
\hline & Based on personal preference & 'To me this means the judging of people based on personal preferences'. \\
\hline & Based on physical attributes & 'Judging someone on the way they appear or how they look'. \\
\hline Nature of stereotypes (8) & Positive or negative & $\begin{array}{l}\text { 'In most cases this will be a negative stereotype but I do believe positive } \\
\text { stereotypes exist'. }\end{array}$ \\
\hline \multirow[t]{8}{*}{ Perception (98) } & Accurate or inaccurate & $\begin{array}{l}\text { 'It is the perception of an individual on a group of people that is not always the } \\
\text { truth.' }\end{array}$ \\
\hline & Based on behaviour & $\begin{array}{l}\text { 'Your general impression you have of someone and their behaviour in specific } \\
\text { situations'. }\end{array}$ \\
\hline & Based on characteristics & 'Like this person is like this, because of certain characteristics'. \\
\hline & Based on ignorance & $\begin{array}{l}\text { 'It is when someone has their own views about certain things or people and } \\
\text { just being ignorant without being informed'. }\end{array}$ \\
\hline & Based on narrow-mindedness & $\begin{array}{l}\text { 'It's an idea of a particular person or maybe an idea towards something where } \\
\text { one is fixated on it and not willing to change their mindset'. }\end{array}$ \\
\hline & Based on occupation & 'General view that one has of a person in that profession'. \\
\hline & Based on past experience & $\begin{array}{l}\text { 'The perception or belief held of these people is subjective as it may be based } \\
\text { on experience or certain encounters with a certain person from a certain } \\
\text { group'. }\end{array}$ \\
\hline & Based on physical attributes & $\begin{array}{l}\text { 'I think stereotyping is the perception that you have about certain people based } \\
\text { on race, gender and so forth'. }\end{array}$ \\
\hline \multirow[t]{2}{*}{ Preconceived ideas (13) } & Accurate or inaccurate & $\begin{array}{l}\text { 'Stereotypes mean some preconceived conclusions or perceptions about things } \\
\text { or people in whatever form, but are not necessarily confirmed to be reality'. }\end{array}$ \\
\hline & Based on ignorance & 'It is preconceived ideas that you have of someone before you have met them'. \\
\hline
\end{tabular}

Do not know the meaning of stereotypes: Some of the participants were unfamiliar with the meaning of stereotypes. However, these participants were then provided with a definition, and the authors made sure that participants clearly understood the meaning of the term.

Generalisations: Stereotypes are viewed by participants to be generalisations made about people based on their behaviour, characteristics, occupation, physical attributes or religion or on past experience or one's own ignorance. When making generalisations about people, certain behaviours, characteristics and thoughts are attributed to them. Generalisations made about others might not always be correct.

Judgement: Stereotyping is making judgements about people. These judgements are based on abilities, background, behaviour, characteristics, ignorance, beliefs, expectations, personal preference and physical attributes. Furthermore, these judgements may or may not be a true reflection of individuals.

Nature of stereotypes: Some of the participants additionally mentioned that stereotypes can be both positive and negative.

Perceptions: A stereotype is a perception created about others. These perceptions may be based on others' behaviour, characteristics, occupation or physical attributes, your own ignorance or narrow-mindedness or past experience. Perceptions held by others may not always be accurate.
Preconceived idea: Participants viewed stereotypes to be preconceived ideas that people have based on their own ignorance. These preconceived ideas may not be an accurate reflection of reality.

It is clear from the results that the themes of generalisation (frequency rate of 164) and categorisation (frequency rate of 121) were articulated the most by participants. Categorisation was also the theme that consisted of the most sub-themes. The following sub-themes were continuously mentioned across most of the themes: accurate or inaccurate, assign characteristics, assign behaviour, based on behaviour, based on characteristics, based on ignorance, based on narrowmindedness, based on past experience and based on physical attributes.

\section{Category 2: Origin of stereotypes}

In this category, participants were requested to provide descriptions of how stereotypes originate. It is evident from the findings that participants have their own opinion of what causes stereotypes. A large number of participants provided similar descriptions of the origin of stereotypes.

Table 3 provides a detailed overview of the themes and subthemes extracted from the data. Findings were substantiated with direct quotes from participants. When requested to provide an account of the origin of stereotypes, the following themes and sub-themes emerged. 
TABLE 3: Origin of stereotypes.

\begin{tabular}{|c|c|c|}
\hline Theme & Sub-theme & Response \\
\hline Do not know the origins of stereotypes ( 7 ) & Unaware of origin & 'I have no idea'. \\
\hline Human nature (23) & From themselves and others & 'Everybody is human, and humans create stereotypes of other people'. \\
\hline \multirow[t]{10}{*}{ Individual differences (53) } & Attitudes & 'Attitude, also the habit of it, you are used to it'. \\
\hline & Disrespect & 'The people do not know each other; they do not have respect for each other'. \\
\hline & Diversity & 'Different cultures and values and beliefs'. \\
\hline & Frustration & 'Frustrations they might have'. \\
\hline & Jealousy & 'They are all just jealous'. \\
\hline & Personality & 'Your character determines if you make stereotypes'. \\
\hline & Poor self-esteem & 'I think that these stereotypes are caused by lack of self-confidence'. \\
\hline & Poor values & "People do not have strong morals and values anymore." \\
\hline & Selfishness & 'Maybe because people only think about themselves and don't take others into thought'. \\
\hline & Spitefulness & 'Many of the stereotypes are a result of ... spitefulness, etc.' \\
\hline \multirow[t]{2}{*}{ Prejudice (15) } & Discrimination & 'People believe that certain things aren't right according to their beliefs, they discriminate'. \\
\hline & Racism & 'I think people still act a little racist'. \\
\hline Primary exposure (45) & Past experience & 'This could be because of past experiences, and then generalise a group of people because of that'. \\
\hline \multirow[t]{10}{*}{ Secondary exposure (252) } & Apartheid & 'The apartheid era all contributed to the current stereotypes we are experiencing'. \\
\hline & Community & 'I really think that society is the main reason for the existence of stereotypes'. \\
\hline & Culture & 'People's culture also plays a role; we do not always understand people's way of doing things'. \\
\hline & Media & 'What people see on TV, and assume it is the same situation as in reality'. \\
\hline & Observation & 'But what I have seen and heard I see it as a cause'. \\
\hline & Politics & 'Politics is the main cause of these stereotypes'. \\
\hline & Religion & ‘Religion ... also play a role'. \\
\hline & Social interaction & 'And your friends around you'. \\
\hline & Upbringing & 'If there is a certain belief in a family then the children will also grow up believing it'. \\
\hline & Workplace & 'It is about where you work and how your work environment is'. \\
\hline \multirow[t]{2}{*}{ Subjective perception (131) } & Ignorance & $\begin{array}{l}\text { 'I would say that people that stereotype do not go through the trouble of getting to know you } \\
\text { better'. }\end{array}$ \\
\hline & Simplification & 'I think it is easier to make an assumption about him rather than getting to know him'. \\
\hline
\end{tabular}

Do not know the origin of stereotypes: Some of the participants indicated that they were unaware from where stereotypes originate from.

Human nature: Participants viewed stereotypes to be human nature; it is something people do, for no particular reason, other than human nature. The participants indicated that stereotypes come from themselves and others.

Individual differences: Not all people stereotype; some stereotype because of factors unique to themselves. People stereotype because they have an attitude or a high selfconcept. Others stereotype because they show no respect for other people or because people frustrate them. Some participants indicated stereotypes are caused by being jealous of others or having a poor self-esteem. Having poor values and being selfish and spiteful were other sub-themes that were mentioned by participants. People also stereotype because they are diverse. These differences can be based on aspects such as beliefs, values and demographic variables.

Prejudice: Participants indicated that stereotypes originate from prejudice. Discrimination, hate and racism are forms of prejudice that can result in stereotyping.

Primary exposure: This refers to stereotyping that is caused by direct experiences that participants have had in the past with a specific person or group. These experiences caused participants to stereotype other persons or groups that are similar to those they had the experience with.

Secondary exposure: Participants mentioned that stereotypes originate from exposure to a variety of influences. It is important to note that these influences are only indirect influences and do not account for any direct experience that participants have had with a particular person or group. These influences include apartheid, the community in which they live, the media (such as TV and newspapers), observation of others, politics of the country, religion that they practise, social interaction with friends and family, upbringing (which includes family and school) and place of employment.

Subjective perception: This refers to people's subjective views of people and objects. People stereotype others because they are ignorant, narrow-minded and judgemental beings. Participants also reported that stereotyping serves as a simplification process: it is easier to stereotype others than to spend time getting to know them personally.

After reviewing Table 3, it is evident that more than half of the participants are of the opinion that stereotypes originate from secondary exposure (response rate of 252), followed by subjective perception (frequency of 131). Individual differences was the theme that consisted of the most sub-themes. 


\section{Discussion Outline of the results}

The first objective of this study was to understand the meaning that employees from various South African organisations attribute to the term 'stereotype'. After a detailed analysis of the findings of this study, it became evident that participants are familiar with the meaning of stereotypes. Only a few of the participants pointed out that the meaning of stereotypes was unknown to them; however, these participants were provided with a detailed description of the term. The participants indicated that different descriptions of stereotypes exist, thereby providing an indication of multiple realities that exist amongst participants. This is in line with social constructivism, in which individuals are inclined to attach different meanings to a certain phenomenon (Mullins, 2010). Therefore, the perception an individual has about a certain phenomenon may be described as their reality and may differ from the next person's reality (Mullins, 2010). This was also evident in the data, since individuals attached various terminologies to the description of stereotypes. The following themes emerged when participants were requested to explain their understanding of stereotypes: assumptions, beliefs, categorisation, differences, discrimination, do not know the meaning of stereotypes, generalisation, ignorance, judgement, narrow-mindedness, nature of stereotypes, perception, preconceived ideas. Sub-themes that emerged continuously throughout the themes included: accurate or inaccurate, assign characteristics, assign behaviour, based on characteristics, based on behaviour, based on ignorance, based on narrow-mindedness and based on physical attributes.

Various literature sources confirm the findings of this study. Colquitt, Lepine and Wesson (2014) elaborate by stating that stereotypes refer to assumptions that are made about individuals based on them belonging to a specific group. Stereotypes aid employees in categorising people, events, situations and objects into preconceived categories that are stored in their long-term memory (Ivancevich, Konopaske \& Matteson, 2014; McShane \& Von Glinow, 2014). Participants of this study mentioned that stereotypes are based on behaviour, characteristics and physical attributes. McShane and Von Glinow (2014) confirm this by indicating that:

stereotyping is the perceptual process in which individuals assign characteristics to an identifiable group and then automatically transfer those features to anyone they believe is a member of that group. (p. 53)

These characteristics that are allocated to these group members are often difficult to observe, such as personality attributes and capabilities; however, they can also encompass physical attributes. Hilton and Von Hippel (1996) suggest that stereotypes are beliefs and views not only about the characteristics of persons, but also about the behaviours of members of certain groups.

A number of participants mentioned that stereotypes can be either positive or negative. Whitley and Kite (2006) agree with this and further state that stereotypes can disadvantage one group, but can simultaneously favour another. Furthermore, as mentioned above, a recurring theme that was mentioned by many participants is the view that stereotypes can be both accurate and inaccurate, which McShane and Von Glinow (2014) concur with. Crawford (2012), together with Whitley and Kite (2006), suggests that it is important to remember that, even if stereotypes hold a kernel of truth for an overall group, they may still be inaccurate when making judgements about individual members of that group. Although stereotypes help individuals to cope with large amounts of information, the consequences of assigning inaccurate stereotypes are very negative. Inaccurate stereotyping can lead to bias and people not succeeding in really getting to know others who are different from them (Mullins, 2010). Although the participants acknowledged that stereotypes can be inaccurate, the participants of this study still engage in the process of stereotyping.

Many participants also hold the view that stereotypes are based on people's own ignorance or narrow-mindedness. Stereotypic beliefs are resistant to change, although social reality is changing and people still stereotype even though they are confronted with new and contrasting information (Crawford, 2012; Von Hippel, Sekaquaptewa \& Vargas, 1995).

Instead of challenging or testing existing stereotypes, individuals view and examine new information in ways that confirm existent stereotypes (Sampson, 1999). This may mean that, although participants are aware of their stereotypes not being true (inaccurate therefore), they still continue to stereotype, because it is easier to do so and saves time, thereby reinforcing existent stereotypes.

\section{Origin of stereotypes}

The second objective of this study was to determine the origin of stereotypes as experienced by employees from selected South African organisations. When evaluating the origin of stereotypes in South African organisations, it was found that participants of the present study are indeed familiar with the factors that cause stereotypes. When participants were requested to explain the origins of stereotypes, the following themes emerged: human nature, individual differences, prejudice, primary exposure, secondary exposure and subjective perceptions. Even though not all of the participants have had direct experiences with stereotypes, they were mindful of the fact that stereotypes also originate from indirect experiences. This can clearly be seen from the results, as most of the participants indicated that stereotypes originate from secondary exposure (i.e. stereotypes that originate due to external influences). Whitley and Kite (2006) confirm this by stating that external influences from sources such as peers, parents and the media contribute to the formation of stereotypes. Most of the participants indicated that stereotypes originate from sources other than the workplace.

Participants indicated that it is human nature to stereotype. Sampson (1999) agrees, saying that stereotyping is a natural 
part of being human. Individuals are bombarded with large amounts of information every day and by stereotyping others, they make it easier for themselves to deal with this information. Within the work setting, individuals interact with many individuals on a daily basis, such as clients, colleagues and supervisors. By engaging in the natural phenomenon of stereotyping, individuals may restrict themselves from getting to know the people they interact with on a daily basis because they do not have the time to get to know each of these individuals on a more personal level.

Furthermore, participants indicated that stereotypes occur because of individual factors unique to each person. Differences between people that were mentioned include jealousy, high self-concept and poor self-esteem. According to Crawford (2012), people want to feel good about themselves and superior to others and therefore they stereotype. In an effort to heighten their self-esteem, they may stereotype their own group (in-group) more positively than other groups to which they do not belong (out-groups); consequently, they undervalue out-groups whilst simultaneously escalating the characteristics of their in-group (Feldman, 2013). It seems that individuals may stereotype others in order to feel good about themselves; however, they do not consider that their stereotypes of others may have the opposite effect on the individuals being stereotyped.

Participants are also of the opinion that stereotypes originate from prejudice. Stereotyping prevents individuals from getting to know others better and leads to individuals maintaining prejudice and discrimination (Sampson, 1999). Although stereotypes, prejudice and discrimination are closely related, one can occur without the others (Plous, 2003). Plous (2003) provides an example by describing that when there are positive or neutral stereotypic beliefs about a racial group such as 'family orientated', this may not lead to prejudice or discrimination. Therefore, when being stereotyped, individuals should not instantaneously view themselves as being prejudiced against; they should rather reflect on the nature of the stereotype given.

Another finding of this study was the perception of participants that stereotypes occur because of primary exposure. For the sake of this study, primary exposure refers to direct past experiences people have had with others belonging to a specific group, for instance a specific race group. Glassman and Hadad (2013) concur and state that stereotypes of a social nature are formed initially from specific experiences or from observing individuals from specific groups. Participants also indicated that stereotypes originate from secondary exposure. Secondary exposure refers to stereotypes that are learned from various external sources such as parents, schools, culture, society, apartheid and so on, and also by observing different people. Relevant literature to support these findings does exist. According to Whitley and Kite (2006, p. 6), stereotypes are learned from a variety of sources such as 'media, peers, parents, and even sources such as classic and modern literature'. Various studies have found that stereotypes are learned by children from the age of three years, and these influence children's perceptions of various social groups (Plous, 2003; Whitley \& Kite, 2006). Cooke-Jackson and Hansen (2008) also found that although stereotyping may be inevitable, stereotypes become problematic when the media incorrectly portray stereotypes. They further state that these stereotypes ignore the richness of the stereotyped group and can result in social inequality for the individuals involved. Individuals who stereotype others should therefore reflect on whether the stereotypes they have are indeed accurate or if it is just a product of being influenced by others.

In addition to the above-mentioned, Durrheim and Talbot (2012) conducted a study amongst Durbanites who grew up in post-apartheid South Africa. The aim of the study was to investigate whether stereotypes about different race groups remained the same after the apartheid era. To their surprise, the findings indicated that racial stereotypes have not changed much despite the historical changes that have taken place in South Africa, thereby suggesting that stereotypes are not fading in post-apartheid South Africa. The conclusion can therefore be drawn that the apartheid era certainly had and still has an influence on stereotypes, whether or not one was directly affected by it. Durrheim and Talbot (2012) and Durrheim, Mtose and Brown (2011) state that regardless of the economic, political and social changes that took place in post-apartheid South Africa, certain race groups are still underrepresented in social status hierarchies and in organisations. The authors share this belief since during data collection it seemed that the workforce was still predominantly white. Durrheim and Talbot (2012, p. 490) further state that 'these lines and categories of privilege are clearly visible in the racial stereotypes that prevail in South Africa today'.

The results of this study also showed that stereotypes occur because of individuals' own subjective perceptions. The perceptions individuals have of others are not necessarily factual and are based on their own subjective opinions of others. The reasons for these subjective perceptions may be people's own narrow-mindedness, lack of knowledge of others or simply the result of a time-saving mechanism. Stereotypes are usually applied by people when they are busy and distracted, because stereotypes serve a mental shortcut function by aiding individuals to process large amounts of information with which they are confronted (Dovidio et al., 2010; Gilbert \& Hixon, 1991). Plous (2003) concludes by suggesting that no matter what the origin of stereotypes, they are self-perpetuating. People have an inclination to notice information that is consistent with their stereotype and to be oblivious to things that do not fit; thus, the self-perpetuating nature of stereotypes (Gibson, Ivancevich, Donnelly \& Konopaske, 2012). Individuals should therefore make an active effort to not stereotype others just because they do not have the time or energy to really get to know someone. By doing this, individuals may realise that embracing the uniqueness of each individual can contribute to a better understanding of all people in the working environment. 


\section{Practical implications}

By participating in this study, individuals may have become aware of the fact that their perceptions and opinions of others may be based on inaccurate information. As a consequence of their participation in this study, individuals may be encouraged to truly get to know someone first before relying on their possibly inaccurate stereotypes. When individuals are aware of where their stereotypes originate from, they should actively attempt not to make use of their stereotypes when coming into contact with stereotyped groups. Organisations should educate their employees on the process of stereotyping and exactly what this means and where stereotypes originate from.

\section{Limitations and recommendations}

There are various limitations with regard to this particular study. The first limitation is with regard to the language that was used to conduct the interviews. It may be possible that some of the participants who completed the interview in their second language may have felt challenged when doing this. This may have caused the participants not to be able to articulate themselves properly. It may also be possible that participants were uncomfortable with the use of tape recorders, thereby not fully disclosing their opinion as they were expected to. Participants did, however, give permission for interviews to be tape-recorded and the authors and fieldworkers did inform the participants that their identities would remain confidential.

The authors of this study explored what the origins of stereotypes are as experienced by employees within the broader South African work context. Therefore, the authors did not ask participants to indicate where specific in-group or out-group stereotypes originate from. By doing this, the researchers only collected a broad view of where stereotypes come from, and were not able to indicate where specific stereotypes (for example those based on race, gender and age) come from. It is suggested that future studies should focus on investigating the origins of specific stereotypes as experienced by individuals. By using the etic ( $\mathrm{Nel}$ et al., 2012) perspective, future researchers can make comparisons regarding the origins of stereotypes based on, for example, race, gender and age.

Stereotypes are automatic and can be activated without awareness; however, people can make a conscious effort to become aware of their automatic stereotyping by fighting against their natural inclination to make stereotypical judgements about others (Crawford, 2012). Being less judgmental involves stopping stereotyping and making use of correct and accurate information when dealing with people. By being open-minded, paying attention and making mindful decisions, stereotyping can be controlled.

According to Whitley and Kite (2006), inaccurate stereotypes need to be changed. When people are faced with evidence that is contradictory to the stereotypical view they have two choices: they can either change the stereotypic belief or they can find a manner in which to recategorise the persons who do not adhere to the stereotype. Stereotyping others should especially be avoided when meeting someone for the first time. Although it is human nature to stereotype, the effects of stereotyping are usually to the detriment of someone else; therefore, it is necessary to identify the stereotypes one holds and the impact thereof on your perception of others (Bergh, 2011).

With regard to recommendations for future research, it is suggested that interviews should beconducted in participants' home language, by employing trained fieldworkers who are proficient in the home language of participants. By doing this, the likelihood exists that participants will understand the line of questioning better, and will feel more comfortable when having the opportunity to answer questions in their home language. This may ensure that participants are given the opportunity to articulate or express themselves more adequately which may lead to more accurate findings. Furthermore, it is recommended that, instead of only making use of qualitative methods of collecting data, a quantitative approach should also be employed, thereby allowing for explanation of the findings as gathered from the qualitative analysis. Although the meaning and origin of stereotypes were explored amongst employees from selected South African organisations in order to collect an overall (broad) view of stereotypes, it may also be interesting to assess how different race, gender, age and occupational groups understand stereotypes and how they originate from their specific viewpoints.

\section{Conclusion}

To conclude, it seems that people employed in selected South African organisations are familiar with stereotypes and have a clear understanding of the concept. Although participants provided different descriptions of the term, as can be confirmed by relevant stereotype literature, there seems to be a consensus amongst participants of this study of what exactly the process of stereotyping entails. Individuals who had partaken in this study also have a conscious awareness of the origin of stereotypes. Although not all of the participants have had direct experiences with stereotyped groups, they are well aware that stereotypes also originate from indirect sources. Although only employees formed part of this study, it is evident that the origins of stereotypes were described by participants in more general terms and not specifically relating to the workplace. In other words, the origins of stereotypes can be contributed to sources that are not specifically found in the workplace context (only six participants mentioned that their stereotyping originated from their workplace); therefore, stereotypes stemming from other origins can be transferred to the workplace. The conclusion can also be drawn that, although individuals are aware of their stereotypic tendencies and nature, they still continue to stereotype others, irrespective of whether these stereotypes are factual or not. 


\section{Acknowledgements Competing interests}

The authors declare that they have no financial or personal relationships that may have inappropriately influenced them in writing this article.

\section{Authors' contributions}

L.B. (North-West University) conducted the data analysis, conducted the final integration of the data and wrote the introduction, literature review, research design, findings, discussion and conclusion. She sent the final draft for language editing and made corrections based on recommendations of language editor. J.A.N. (North-West University) shortened the article for publication purposes, reviewed the data analysis, provided feedback on the final integration of data and provided feedback on the final copy of the manuscript.

\section{References}

Adhikari, M. (2006). 'God made the white man, God made the black man...' Popular racial stereotyping of Coloured people in apartheid South Africa. South African Historical Journal, 55(1), 142-164. http://dx.doi.org/10.1080/0258247 0609464935

Allport, G.W. (1954). The nature of prejudice. Cambridge, MA: Harvard University Press.

Arnold, J., Randall, R., Patterson, F., Silverster, J., Robertson, I., Cooper, C. et al. (2010). Work psychology: Understanding human behaviour in the workplace. (5th edn.). Harlow, England: Pearson Education Limited.

Barkley, L. (1982). Social learning theory: A framework for discrimination research. Academy of Management Review, 7(4), 587-594. http://dx.doi.org/10.2307/ 257225

Bar-Tal, D. (1996). Development of social categories and stereotypes in early childhood: The case of the "The Arab" concept formation, stereotype and attitudes by Jewish children in Israel. International Journal of Intercultural Relations, 20(3), 341-370. http://dx.doi.org/10.1016/0147-1767(96)00023-5

Bergh, Z. (2011). Sensory and perceptual processes in work behaviour. In Z. Bergh (Ed.), Introduction to work psychology (pp. 110-133). Cape Town, South Africa: Oxford University Press.

Bergh, Z.C., \& Theron, A.L. (2009). Psychology in the work context. (4th edn.). Cape Town, South Africa: Oxford University Press.

Botma, Y., Greeff, M., Mulaudzi, F.M., \& Wright, S.C.D. (2010). Research in health sciences. Cape Town, South Africa: Pearson Education South Africa.

Braun, V., \& Clarke, V. (2006). Using thematic analysis in psychology. Qualitative Research in Psychology, 3, 77-101. http://dx.doi.org/10.1191/1478088706qp063oa

Colquitt, J.A., Lepine, J.A., \& Wesson, M.J. (2014). Organizational behaviour: Improving performance and commitment in the workplace. (2nd edn.). New York, NY: McGraw-Hill.

Cooke-Jackson, A., \& Hansen, E.K. (2008). Appalachian culture and reality TV: The ethical dilemma of stereotyping others. Journal of Mass Media Ethics, 23(3), 183200. http://dx.doi.org/10.1080/08900520802221946

Crawford, M. (2012). Transformations: Women, gender and psychology. (2nd edn.) New York, NY: McGraw-Hill Higher Education.

Creswell, J.W. (2009). Research design: Qualitative, quantitative, and mixed method approaches. (3rd edn.). Thousand Oaks, CA: Sage Publications.

De Vos, A.S., Strydom, H., Fouché, C.B., \& Delport, C.S.L. (2011). Research at grass roots: For the social sciences and human service professions. (4th edn.). Pretoria, South Africa: Van Schaik Publishers.

Dovidio, J.F., Hewstone, M., Glick, P., \& Esses, V.M. (2010). Prejudice, stereotyping and discrimination: Theoretical and empirical overview. In J.F. Dovidio, M. Hewstone, P. Glick, \& V.M. Esses (Eds.), The Sage handbook of prejudice, stereotyping and discrimination (pp. 3-28). Thousand Oaks, CA: Sage Publications Ltd. http://dx.doi.org/10.4135/9781446200919.n19

Durrheim, K., Mtose, X., \& Brown, L. (2011). Race trouble: Race, identity and inequality in post-apartheid South Africa. Pietermaritzburg, South Africa: University of KwaZulu-Natal Press.

Durrheim, K., \& Talbot, K. (2012). The Princeton trilogy revisited: How have racial stereotypes changed in South Africa? South African Journal of Psychology, 42(4), 476-491.
Durrheim, K., \& Wassenaar, D. (2002). Putting design into practice: Writing and evaluating research proposals. In M. Terre Blanche, \& K. Durrheim (Eds.), Research in practice: Applied methods for the social sciences (pp. 54-71). Cape Town, South in practice: Applied methods for the

Feldman, R.S. (2013). Understanding psychology. (11th edn.). New York, NY: McGrawHill Higher Education.

Gibson, J.L., Ivancevich, J.M., Donnelly, J.H., \& Konopaske, R. (2012). Organizations: Behavior, structure, processes. (14th edn.). New York, NY: McGraw-Hill Higher Education.

Gilbert, D.T., \& Hixon, J.G. (1991). The trouble of thinking activation and application of stereotypic beliefs. Journal of Personality and Social Psychology, 60(4), 509-517. $\mathrm{http}: / / \mathrm{dx}$.doi.org/10.1037/0022-3514.60.4.509

Glassman, W.E., \& Hadad, M. (2013). Approaches to psychology. (6th edn.). New York, NY: McGraw-Hill Higher Education.

Hansen, J.T. (2004). Thoughts on knowing: Epistemic implications of counselling practice. Journal of Counselling \& Development, 82(2), 131-138. http://dx.doi. org/10.1002/j.1556-6678.2004.tb00294.x

Hilton, J.L., \& Von Hippel, W. (1996). Stereotypes. Annual Review of Psychology, 47(1), 237-271. http://dx.doi.org/10.1146/annurev.psych.47.1.237

Holtzhausen, T., Jordaan, Y., \& North, E.J. (2011). The portrayal of women in South African television commercials. Southern African Business Review, 15(3), 167-183.

Ivancevich, J.M., Konopaske, R., \& Matteson, M.T. (2014). Organizational behavior and management. (10th edn.). New York, NY: McGraw-Hill Higher Education.

Jenifer, R.D., \& Raman, G.P. (2015). Cross-cultural communication barriers in the workplace. International Journal of Management, 6(1), 348-351.

Jussim, L. (2012). Social perception and social reality: Why accuracy dominates bias and self-fulfilling prophecy. New York, NY: Oxford University Press. http://dx.doi. org/10.1093/acprof:oso/9780195366600.001.0001

Lee, Y., Jussim, L., \& McCauley, C.R. (2013). Stereotypes as categories of knowledge: Complexity, validity and usefulness, and essence in perception of group differences. Advances in Psychological Science, 21(1), 1-21. http://dx.doi.org/ differences. Advances in Psychol
10.3724/SP.J.1042.2013.00001

Lippmann, W. (1922). Public opinion. New York, NY: Harcourt, Brace.

Luthans, F. (2010). Organizational behaviour: An evidence-based approach. (12th edn.). New York, NY: McGraw Hill.

Maree, K., \& Pietersen, J. (2010). Sampling. In K. Maree (Ed.), First steps in research (pp. 171-181). Pretoria, South Africa: Van Schaik Publishers.

McShane, S., \& Von Glinow, M. (2014).Organizational behaviour. (2nd edn.). New York, NY: McGraw-Hill Higher Education.

Mullins, L.J. (2010). Management and organisational behaviour. (9th edn.). Harlow, England: Pearson Education Limited.

Nel, J.A., Valchev, V.H., Rothmann, S., Van de Vijver, F.J.R., Meiring, D., \& De Bruin, G.P. (2012). Exploring the personality structure in 11 languages of South Africa. Journal of Personality, 80(4), 915-948. http://dx.doi.org/10.1111/j.14676494.2011.00751.x

Niewenhuis, J. (2010). Introducing qualitative research. In K. Maree (Ed.), First steps in research (pp. 46-68). Pretoria, South Africa: Van Schaik Publishers.

Pickering, M. (2001). Stereotyping: The politics of representation. New York, NY: Palgrave Publishers Ltd.

Plous, S. (2003). The psychology of prejudice, stereotyping, and discrimination: An overview. In S. Plous (Ed.), Understanding prejudice and discrimination (pp. 3-48). New York, NY: McGraw-Hill.

Ramasubramanian, S. (2005). Comparative media stereotyping: How media content about one group influences prejudicial feelings towards another group. Paper presented at the 55th Annual Conference of the International Communication presented at the 55th Annual Conference of the Internation
Association (Mass Communication Division), New York, NY.

Sampson, E.E. (1999). Dealing with differences: An introduction to the social psychology of prejudice. Orlando, FL: Harcourt College Publishers.

Stangor, C., Lynch, L., Duan, C., \& Glass, B. (1992). Categorization of individuals on the basis of multiple social features. Journal of Personality and Social Psychology, 62(2), 207-218. http://dx.doi.org/10.1037/0022-3514.62.2.207

Timberlake, J., \& Estes, S. (2007). Do racial and ethnic stereotypes depend on the sex of target group members? Evidence from a survey-based experiment. The Sociological Quarterly, 48(3), 399-433. http://dx.doi.org/10.1111/j.1533-8525. 2007.00083.x

Von Hippel, W., Sekaquaptewa, D., \& Vargas, P. (1995). On the role of encoding processes in stereotype maintenance. Advances in Experimental Social Psychology, 27, 177-254. http://dx.doi.org/10.1016/S0065-2601(08)60406-2

Welman, C., Kruger, F., \& Mitchell, B. (2005). Research methodology. Cape Town, South Africa: Oxford University Press.

Wessels, P.L., \& Steenkamp, L.P. (2009). An investigation into students' perceptions of accountants. Meditari Accountancy Research, 17(1), 117-132. http://dx.doi. of accountants. Meditari Accounton
org/10.1108/10222529200900008

Whitley, B.E. Jr., \& Kite, M.E. (2006). The psychology of prejudice and discrimination Belmont, CA: Thompson Wadsworth.

Yin, R. (1994). Case study research: Design and methods. (2nd edn.). Thousand Oaks, CA: Sage Publishing. 